\title{
Antioxidants Attenuate the Effects of Insulin Dependent Diabetes Mellitus on Sperm Quality
}

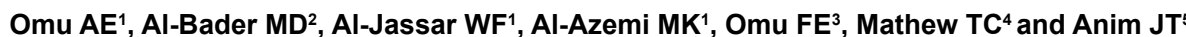

${ }^{1}$ Department of Obstetrics and Gynaecology, Faculty of Medicine, Health Sciences Center, Kuwait University, Kuwait

${ }^{2}$ Department of Physiology, Faculty of Medicine, Health Sciences Center, Kuwait University, Kuwait

${ }^{3}$ Department of PAAET, College of Nursing, Kuwait University, Kuwait

${ }^{4}$ Department of Anatomy, Faculty of Medicine, Health Sciences Center, Kuwait University, Kuwait

${ }^{5}$ Department of Pathology, Faculty of Medicine, Health Sciences Center, Kuwait University, Kuwait

\begin{abstract}
Introduction: The prevalence of Diabetes Mellitus has been increasing in an epidemic proportion worldwide and it is associated with impairment of sperm quality and cause infertility. The role of antioxidants therapy to improve human sperm quality has not been established.
\end{abstract}

Objective of study: To investigate the effect of antioxidants therapy on sperm quality in men with insulin dependent diabetes mellitus.

Materials and methods: Forty-five men with insulin dependent diabetes attending the andrology clinic, between January 2008 and December 2012 seen at the Maternity Hospital, Kuwait, form the subjects of this study. Thirty nondiabetic infertile men matched for age and duration of infertility formed the control group. The study protocol included initial pretherapy and post-therapy clinical evaluation of all the patients, semen analysis, hormone profile, glycosylated haemoglobin $\left(\mathrm{HbA}_{1} \mathrm{C}\right)$, Malonedialdehyde (MDA), lipid profile, Acridine orange denaturation of sperm for evaluation of sperm DNA fragmentation index and light and electron microscopy. The patients were administered Zinc, Selenium and vitamins $\mathrm{E}$ and $\mathrm{C}$ for three months and revaluated.

Results: Diabetes mellitus was associated with significantly impaired sperm motility (asthenozoospermia) compare to control $(64 \%$ versus $36 \%)(P<0.05)$, normal sperm morphology $(66 \%$ versus $52 \%)(p<0.05)$, higher $\mathrm{HbA}_{1} \mathrm{C}(9.6 \%$ versus $4.4 \%, \mathrm{P}<0.05)$ and oxidative stress (MDA) $(2.4$ versus $1.4 \mathrm{nmol} / \mathrm{L}, \mathrm{P}<0.01)$ and reduced antioxidant status. Antioxidant therapy significantly decreased glucose level, 18-40\% $p<0.05 ; \mathrm{HbA}_{1}$ c 9-29\% $\mathrm{p}<0.05 ;$ MDA level 33-41\%, $\mathrm{P}<0.01$; and Sperm DNA Fragmentation index, 23-33\%, $\mathrm{p}<0.01$ ) and Increase in BuChE 21-40\%, p<0.05 and TAC, $27-$ $36 \%, p<0.05$.

Conclusion: Diabetes mellitus particularly with poor glycemic control is associated with impaired sperm quality, involving oxidative stress in the pathogenesis. Antioxidant therapy has been shown to significantly improve the sperm quality.

Keywords: Diabetes mellitus; Oxidative stress; Sperm quality; Antioxidant

\section{Lay summary}

This study was conducted to evaluate the protective effects of antioxidants on sperm quality of men with insulin dependent diabetes mellitus. The study involved 45 diabetic men on insulin therapy and 30 non-diabetic infertile men as controls. Both groups were seen and evaluated the infertility clinic of the Maternity Hospital, Kuwait. They had semen analysis and estimation of lipid and hormone profiles, malonidialdehyde (MDA) a marker of oxidative stress, glycosylated haemoglobin $\left(\mathrm{HbA}_{1} \mathrm{c}\right.$ ) (with low value of below 7\% as evidence of good diabetic control) and sperm DNA damage. Both groups of men were administered Zinc, selenium, vitamins $\mathrm{C}$ and $\mathrm{E}$ for three months. The investigations above were then repeated.

The results of this study showed that diabetes mellitus was significantly associated with impaired sperm motility and abnormal sperm morphology, higher glycosylated haemoglobin, oxidative stress and sperm DNA damage. Interestingly, after three months of administration of antioxidants there was decreased serum glucose level, oxidative stress (MDA), $\mathrm{HbA}_{1} \mathrm{c}$, sperm DNA damage and increased total antioxidant activity and obvious improvement of sperm parameters. We advocate dietary consumption of food rich in antioxidants, especially fruits and leafy vegetables that are rich in natural antioxidants and antioxidant supplementation by diabetic men, to prevent the oxidative effectof diabetes on sperm to cause infertility and other non-fertility complications in diabetic men.

\section{Introduction}

Diabetic epidemic will continue to rise and in 2030 will be $4.4 \%$ from $2.8 \%$ in 2000 and the number of diabetes will reach 366 million by 2030 [1], with potentially devastating effect and expensive treatment. More recent global estimates involving 216 countries put prevalence of diabetes of diabetes in the adult population at $6.4 \%$ affecting 285 million in 2010 to $7.7 \%$ in 439 million adults by 2030 [2]. Current

*Corresponding author: Omu AE, Department of Obstetrics and Gynaecology Faculty of Medicine, HSC, Kuwait University, PO Box: 24923, Safat13110, Kuwait, Tel: 009652498 6458; Fax: 00965 5338906; E-mail: Omu@hsc.edu.kw

Received January 24, 2014; Accepted February 20, 2014; Published February 22, 2014

Citation: Omu AE, Al-Bader MD, Al-Jassar WF, Al-Azemi MK, Omu FE, et al. (2014) Antioxidants Attenuates the Effects of Insulin Dependent Diabetes Mellitus on Sperm Quality. Bioenergetics 3: 113. doi:10.4172/2167-7662.1000113

Copyright: @ 2014 Omu AE, et al. This is an open-access article distributed unde the terms of the Creative Commons Attribution License, which permits unrestricted use, distribution, and reproduction in any medium, provided the original author and source are credited. 
prevalence estimates for diabetes mellitus in Arabian Gulf countries are some of the highest in the world [3]. The overall prevalence of diabetes in Saudi Arabia is about 30\% [4]. The prevalence of diabetes in adult Kuwait population is spreading to children and adolescents, making it an emergency public health problem [5]. Diabetes mellitus (DM) is a chronic metabolic disorder characterized by hyperglycemia caused by abnormal insulin production, insulin resistance or often both and a major cause of serious micro and macrovascular complications, affecting nearly every system in the body [6]. $\mathrm{HbA}_{1} \mathrm{c}$ has been used to measure blood sugar control over an extended period in people with diabetes. If the $\mathrm{HbA}_{1} \mathrm{c}$ value is above $7 \%$, it means the diabetes is poorly controlled and the higher the $\mathrm{HbA}_{1} \mathrm{c}$ value, the higher the risk of development of diabetic complications. The American Diabetes Association (ADA) has recently set the cut-offpoint at 6.5\% [7].

\section{Diabetes mellitus and Oxidative stress}

The literature is replete with evidence that oxidative stress is increased in diabetes mellitus due to overproduction of free radicals such as reactive oxygen species (ROS) and decreased efficiency of antioxidant defenses [6], through increased production of advanced glycated end-products (AGEs) and mitochondrial damage [8,9]. DM is associated with increased oxidative stress which damages sperm nuclear and mitochondrial DNA [9]. By altering sperm membrane integrity, ROS may impair sperm motility as well as sperm viability and cause DNA damage through sperm membrane lipid peroxidation. Although diabetes mellitus (DM) is known to cause many systemic complications [10], erectile dysfunctions like impotence, and Hypogonadism (11), male infertility is not widely recognized [12] and appropriately evaluated as a complication of diabetes mellitus [13].

Role of antioxidantsin subfertilemen with diabetesmellitus:There is paucity of studies and inconsistencies regarding impact of diabetes mellitus (DM) on semen quality and the role of antioxidants. Several studies report an improvement in sperm parameters when treating $\mathrm{T}_{2} \mathrm{DM}$ patientswith a wide range of antioxidants [14-19]. Unfortunately, most of these data concerning intervention with antioxidants are from animal models. In streptozotocin rats-induce INND in rats-hydrated C (60) fullerence [C(60) HyFn], a known powerful bio antioxidant eliminated testicular dysfunction induced by STZ-diabetes in ratssignificantly reduced diabetes induced oxidative stress and associated complications such as testicular dysfunction and spermatogonic disruption [14]. In recent studies in rats, ellagic acid (EA) administration to adrimycin (ADR) treated rats provided significant improvement in ADR induced disturbed oxidant/antioxidants balance, decreased testosterone concentrations and testicular apoptosis [16], showing that EA has protective effects on ADR induced testicular lipid peroxidation and apoptosis. Administration of lycopene and ellagic acid eliminated arcolor (AR) 1254 induced testicular and spermatozoal toxicity and reproductive dysfunction associated with oxidative stress and apoptosis in male rats [16]. In a randomized double-blind placebo controlled trial with oral vitamin $\mathrm{E}$ showed significantly improved sperm motility in $60 \%$ of asthenozoospermic patients compared to $11 \%$ in those placed on placebo [17]. In another study, a combination of selenium with vitamin C (10 mg), significantly improved sperm motility [18]. We have previously demonstrated that oral Zinc sulphate $250 \mathrm{mg}$ administration in asthenozoospermic men resulted in improvement of all standard sperm parameters [19]. All these last three studies included mixed groups of men as their study subjects and therefore could not show the effects of diabetes.

To our knowledge the role of antioxidants in the association of diabetes mellitus and human sperm quality, has not been fully established. The increasing incidence of DM worldwide will inevitably result in a higher prevalence of diabetes related infertility [20]. A recent study reported that 35 percentof type 2 diabetes is infertile [12]. Young male diabetic patients are likely to present high infertility/subfertility prevalence resulting from impaired reproduction function and poor semen quality [21].

\section{Objective of study}

To investigate the effect of antioxidants on improving the adverse effect of poor glycaemic control on sperm quality in males with insulin dependent diabetes mellitus with operative hypothesis that zinc, selenium and antioxidants vitamins $\mathrm{C}$ and $\mathrm{E}$ may have protective effects on oxidative stress induced impairment of the sperm parameters of diabetic men.

\section{Materials and Methods}

Forty five men with insulin dependent diabetes and thirty nondiabetic infertile men as control, attending the combined infertility clinic, between January 2008 and December 2012 at the Maternity Hospital, Kuwait were evaluated. Ethical approval by the institutional board of the Faculty of Medicine Kuwait University was obtained before the commencement of the study.

To be included in the study, the men must have been cohabiting with their spouses without the use of contraception for at least 12 months, nonsmokers and not on drugs for/and history of chronic diseases for the past 6 months, blood pressure less than 140/90 mm $\mathrm{Hg}$ and body mass index $\leq 30 \mathrm{~kg} / \mathrm{m}^{2}$. All the diabetic patients were on insulin at consultation or were commenced on insulin after referral to the diabetic clinic.

Thirty men in control group were matched for age, duration of infertility and body mass index with the study, cohabited with their spouses for at least 12 months or more and not on drugs for chronic condition like hypertension. All the men had normal fasting blood glucose of $<5.3 \mathrm{mmol} / \mathrm{lt}$ to make sure they were not diabetic

The metabolic control of the diabetes was assessed by $\mathrm{HbA}_{1} \mathrm{c}$. The study protocol included initial clinical evaluation of both patients and controls. Semen analysis, lipid and hormone profiles: LH, FSH and Testosterone; $\mathrm{HbA}_{1} \mathrm{c}$; total antioxidant capacity (TAC), superoxide dismutase (SOD), glutathione peroxidase (GPX); Malonedialdehyde (MDA), electron microscopy of sperm and Sperm DNA fragmentation were carried out before and after the patients were treated with Zinc $250 \mathrm{mg}$, Selenium $300 \mu \mathrm{g}$ and vitamins E $20 \mathrm{mg}$ and C $10 \mathrm{mg}$ twice daily for three months.

\section{Semen analysis}

After 3-day-sexual abstinence, semen samples produced by masturbation were collected into sterile specimen cups and allowed to liquefy at room temperature. Semen analysis was determined according to WHO guidelines [22] using $5 \mu$ l of semen on a Makler chamber.

\section{Blood sample preparation}

Blood was collected from patients after overnight fast by venipuncture into EDTA tubes andserum separated by density centrifugation using a Ficoll-Paque/EPlus centrifuge (Pharmacia Biotech, Uppsala, Sweden) and stored at $-20^{\circ} \mathrm{C}$ for testosterone, Follicle stimulating hormone (FSH) and Luteinizing hormone (LH) levels measured by radioimmunoassay and lipid profiles, and for malonialdehyde (MDA), and superoxide dismutase (SOD), glutathione 
Citation: Omu AE, Al-Bader MD, Al-Jassar WF, Al-Azemi MK, Omu FE, et al. (2014) Antioxidants Attenuates the Effects of Insulin Dependent Diabetes Mellitus on Sperm Quality. Bioenergetics 3: 113. doi:10.4172/2167-7662.1000113

Page 3 of 9

peroxidase (GPX) and total antioxidant capacity (TAC).

\section{Estimation of MDA a marker of Oxidative Stress}

For MDA estimation, into $1.0 \mathrm{ml}$ of serum, $0.5 \mathrm{ml}$ of $350 \mathrm{~g} / \mathrm{L}$ trichloroacetic acid (TCA), and $1.0 \mathrm{ml}$ of $0.5 \%$ thiobarbituric acid were added and mixed. The mixture was incubated at $60^{\circ} \mathrm{C}$ for $90 \mathrm{~min}$. After cooling at room temperature, $1.0 \mathrm{ml}$ of $700 \mathrm{~g} / \mathrm{L}$ TCA and $2.0 \mathrm{ml}$ of chloroform were added, mixed and centrifuged at $1500 \mathrm{~g}$ for $20 \mathrm{~min}$. The absorbancy of the sample supernatant was measured at $532 \mathrm{~nm}$.

\section{Enzymatic estimation of Antioxidants}

SOD, GPX and TAC were estimated colorimetrically using a commercially available kit (Randox Lab, UK) strictly according to the manufacturer's instructions.

Glucose was measured by the hexokinase method (Glucoquant;Boehringer-Mannheim).

\section{Estimation of lipid profile}

Five $\mathrm{ml}$ of venous blood samples were drawn from all subjects under all aseptic precautions. Thereafter, the blood was allowed to clot (for $10 \mathrm{~min}$ ) and serum was separated by centrifugation at $2500 \mathrm{rpm}$ for $20 \mathrm{~min}$. Each serum sample from different groups was evaluated for using diagnostic kit for Total cholesterol (mg/dl), Triglyceride (mg/ $\mathrm{dl})$ and HDL-cholesterol (mg/dl). LDL-cholesterol (mg/dl) and VLDLcholesterol (mg/dl) were calculated using Friedewald formula.

\section{Chromatographic method for $\mathrm{HbA}_{1} \mathrm{c}$}

The chromatographic assay uses an HPLC instrument (LC module) with pump, injector and UV detector of $292 \mathrm{~nm}$ filter (Millipore Corporation, Milford, MA, USA) and ion exchange or affinity column to separate $\mathrm{HbA}_{1} \mathrm{c}$ molecules from other hemoglobin molecules. The $\mathrm{HbA}_{1} \mathrm{c}$ content is calculated based on the ratio of $\mathrm{HbA}_{1} \mathrm{c}$ peak area to the total hemoglobin peak areas.

\section{Hormone profile-FSH, LH and Testosterone by radioimmunoassay}

The serum levels of FSH, LH and Testosterone were determined in the blood by an in vitro assay.

\section{Sperm DNA fragmentation index}

This was determined by Sperm chromatin Structure Assay (SCSA) using Acridine orange denaturation as described by Evenson and Jost [23] and assessed with fluorescence microscopy. Two to three hundred spermatozoa denatured by acridine orange (AO) were counted and percentage of red colored spermatozoa designated as sperm DNA fragmentation (DFI).

Histology: Formaldehyde-fixed semen samples were embedded in paraffin and then sliced (slice thickness, 3-4 $\mu \mathrm{m}$ ) on silaneprecoated slides, deparaffined with xylol, and histologic observations were performed after staining by the hematoxylin-eosin method and assessed with light microscopy.

Electron Microscopy of Spermatozoa: Semen samples were washed three times with phosphate buffer $(0.1 \mathrm{~mol} / \mathrm{L}, \mathrm{pH} 7.4)$, pelleted by centrifugation, fixed in $3 \%$ glutaraldehyde followed with $1.3 \%$ osmium tetroxide, then embedded in Epon Araldite and section photographed by a Seiss 109 Electron Microscope (Zeiss Oberkohen, Germany) after double staining with uranyl acetate and lead citrate.

Statistical analysis: Data entry was carried out on SPSS version 17 , with release $4.1 / 4.0$ for logistic regression and one way analysis

\begin{tabular}{|c|c|c|c|c|c|}
\hline & All Diabetes & $\begin{array}{l}<7 \%\left(\mathrm{HbA}_{1} \mathrm{c}\right) \\
\mathrm{N} 0=26\end{array}$ & $\begin{array}{l}\geq 7 \%\left(\mathrm{HbA}_{1} \mathrm{c}\right) \\
\mathrm{N}=19\end{array}$ & $\begin{array}{l}\text { Control } \\
\mathrm{N}=30\end{array}$ & $\begin{array}{l}\text { P Value } \\
\text { All diabetic } \\
\text { vs Control }\end{array}$ \\
\hline Age (years) & $34.6 \pm 6.4$ & $34.4 \pm 6.8$ & $34.8 \pm 6.4$ & $33.4 \pm 8.2$ & NS \\
\hline Duration of Diabetes (years) & $4.8 \pm 2.6$ & $4.6 \pm 2.5$ & $5.1 \pm 2.7$ & - & - \\
\hline $\begin{array}{l}\text { Semen Parameters } \\
\text { Semen volume }(\mathrm{ml}) \\
\text { Total sperm count }(\mathrm{m} / \mathrm{ml}) \\
\text { Progressive sperm motility }(\%) \\
\text { Asthenozoospermia }(\%) \\
\text { Sperm morphology }(\%)\end{array}$ & $\begin{array}{l}3.6 \pm 1.8 \\
18.8 \pm 8.7 \\
26.2 \pm 13.2 \\
66 \\
52.8 \pm 24.2\end{array}$ & $\begin{array}{l}3.6 \pm 1.4 \\
19.2 \pm 8.8 \\
26.2 \pm 12.4 \\
58 \\
52.3 \pm 24.6\end{array}$ & $\begin{array}{l}3.6 \pm 2.0 \\
18.6 \pm 10.6 \\
24.6 \pm 14.3 \\
74 \\
56.4 \pm 21.3\end{array}$ & $\begin{array}{l}3.4 \pm 2.2 \\
20.4 \pm 8.9 \\
32.4 \pm 14.5 \\
36 \\
66.2 \pm 24.4\end{array}$ & $\begin{array}{l}\text { NS } \\
0.05 \\
0.05 \\
0.01 \\
0.05\end{array}$ \\
\hline $\begin{array}{l}\text { Lipid Profile } \\
\text { Cholestrol (mmol/L) } \\
\text { Triglyceride }(\mathrm{mmol} / \mathrm{L}) \\
\text { HDL }(\mathrm{mmol} / \mathrm{L}) \\
\text { V. LDL }(\mathrm{mmol} / \mathrm{L}) \\
\text { LDL }(\mathrm{mmol} / \mathrm{L})\end{array}$ & $\begin{array}{l}5.2 \pm 2.4 \\
2.2 \pm 0.8 \\
0.8 \pm 0.6 \\
1.0 \pm 0.4 \\
4.2 \pm 1.8\end{array}$ & $\begin{array}{l}4.8 \pm 2.4 \\
1.8 \pm 0.6 \\
1.2 \pm 0.8 \\
0.8 \pm 0.4 \\
3.6 \pm 1.6\end{array}$ & $\begin{array}{l}5.6 \pm 2.2 \\
2.5 \pm 0.8 \\
0.4 \pm 0.2 \\
1.2 \pm 0.4 \\
4.8 \pm 2.1\end{array}$ & $\begin{array}{l}3.6 \pm 1.4 \\
1.4 \pm 0.6 \\
1.3 \pm 0.8 \\
0.5 \pm 0.2 \\
2.2 \pm 0.8\end{array}$ & $\begin{array}{l}0.02 \\
0.05 \\
0.01 \\
0.05 \\
0.05\end{array}$ \\
\hline $\begin{array}{l}\text { Hormone Profile } \\
\text { FSH (iu/L) } \\
\text { LH (iu/L) } \\
\text { Testoserone }\end{array}$ & $\begin{array}{l}5.6 \pm 2.0 \\
6.1 \pm 2.2 \\
14.2 \pm 4.8\end{array}$ & $\begin{array}{l}5.4 \pm \pm 1.8 \\
6.1 \pm 2.4 \\
14.8 \pm 4.6\end{array}$ & $\begin{array}{l}5.8 \pm 2.2 \\
6.0 \pm 1.8 \\
13.8 \pm 5.2\end{array}$ & $\begin{array}{l}6.4 \pm 3.2 \\
5.8 \pm 2.8 \\
16.8 \pm 4.4\end{array}$ & $\begin{array}{l}\text { NS } \\
\text { NS } \\
0.05\end{array}$ \\
\hline
\end{tabular}

$\geq 7 \%$ (Poor glycaemic control) versus good glycaemic control

Progressive motility $\mathrm{P}<0.05$

Asthenozoospermia $\mathrm{P}<0.01$

Sperm morphology $\mathrm{P}<0.05$

Hormone profile

Testosterone $\mathrm{P}<0.05$

Lipid profile

Triglyceride $\mathrm{P}<0.05$

HDL $P<0.05$

LDL/N.LDL $P<0.05$

Diabetes mellitus is associated with poor sperm parameters, abnormal lipid profile and lower testosterone level than in control patients

Table 1: Demographic and Clinical characteristics of study patients Diabetic men with $\mathrm{HbA}_{1} \mathrm{C}$ 
Citation: Omu AE, Al-Bader MD, Al-Jassar WF, Al-Azemi MK, Omu FE, et al. (2014) Antioxidants Attenuates the Effects of Insulin Dependent Diabetes Mellitus on Sperm Quality. Bioenergetics 3: 113. doi:10.4172/2167-7662.1000113

Page 4 of 9

of variance. Results are expressed as means \pm SEM. Levene analysis of variance and Student's $\mathrm{t}$ and $\mathrm{z}$ tests for paired datawas used to determine the significance of differences between pre and post-therapy results. The level of statistical significance was set at $\mathrm{P}<0.05$ for multiple comparisons. All analyses were performed on StatView 5.0 for the Macintosh (Abacus Concepts, Berkeley, CA)

\section{Results}

The patients were on two main types of insulin, namely Intermediate acting (NPH) insulin take twice daily and long acting taken once daily. There were no significant differences in the age and duration of diabetes mellitus between the two study groups and controls. The mean $\mathrm{HbA}_{1} \mathrm{c}$ value in diabetic patients was $8.8 \pm 4.1 \%$ (range 4.0-13.4) versus $4.6 \pm$ $2.8 \%$, for the control group $(\mathrm{P}<0.05)$. With the diabetic men structured according to their level of $\mathrm{HbA}_{1} \mathrm{c}(<7 \%$ for good glycemic control and $\geq 7 \%$ for poor glycemic control, $42.2 \%(19 / 45)$ had poor glycemic control. The prevalence of poor glycemic control was higher at $51.1 \%$ if the new IDA cut-off of $6.5 \%$ or higher for glycemic control.

\section{Effect of diabetes mellitus on sperm parameters}

As shown in Table 1, men with diabetes were more significantly associated with poor sperm parameters compared to the control patients $(\mathrm{P}<0.05)$. Similarly, poor diabetic control in form of $\mathrm{HbA}_{1} \mathrm{C}$ $\geq 7 \%$ was significantly associated with impaired sperm motility; progressive motility, $\mathrm{p}<0.05$, asthenozoospermia $(\mathrm{P}<0.01)$ and normal morphology $(\mathrm{p}<0.02)$. Similarly, men with $\geq 7 \%\left(\mathrm{HbA}_{1} \mathrm{c}\right)$, were significantly associated with abnormal lipid profile; cholesterol $(\mathrm{p}<0.05)$, triglyceride $(\mathrm{p}<0.05)$, LDL $(\mathrm{p}<0.01)$ and VLDL $(\mathrm{p}<0.05)$ and lower HDL $(\mathrm{p}<0.05)$. There was no association between glycemic control and FSH and LH. However Testosterone was higher in the control group than in the study diabetic group $(\mathrm{P}<0.01)$ and reduced with poor diabetic control $(\mathrm{P}<0.05)$.

Figure 1 show typical micrograph of Haematoxylin and Eosin staining of control and diabetic patients. Figure 2 staining pattern of Acridine orange acid denaturation of sperm DNA, to evaluate sperm DNA fragmentation, and Figure 3 for evaluation of sperm morphology by transmission electrom microscopy. As shown in Table 2 and Figure 4 , there was a strong association between poor diabetic control $\left(\mathrm{HbA}_{1} \mathrm{c}\right.$ $\geq 8 \%)$ and sperm defects (teratozoospermia); double head $(\mathrm{p}<0.05)$, round and elongated spermatid $(\mathrm{p}<0.05)$ and cytoplasmic mid and tail piece $(\mathrm{p}<0.05)$. Leukocytoospermia, an index of inflammatory process was also more common in diabetic men with $\mathrm{HbA}_{1} \mathrm{c} \geq 7 \%$.

Antioxidants therapy was associated with improved sperm quality as shown in Table 3 in form of sperm count, $47-57 \%,(\mathrm{P}<0.01)$; progressive motility, 35-38\%, $(\mathrm{P}<0.01)$; asthenozoospermia, $44-48 \%$, $(\mathrm{p}=0.01)$ and normal sperm morphology,16-26\%, $(\mathrm{P}<0.05)$. The differences observed were much stronger when diabetic men with $\geq 7 \%$ $\mathrm{HbA}_{1} \mathrm{c}$ were compared with those with initial glycemic control $(<7 \%$ $\mathrm{HbA}_{1} \mathrm{c}$ ) as shown in Figure 5.

In Figure 6, effect of antioxidant therapy is compared between poor glycaemic control versus good control. As shown in Table 3 , there was positive correlation between serum glucose level and $\mathrm{HbA}_{1} \mathrm{c}(\mathrm{r}=0.625, \mathrm{p}<0.001)$, MDA $(\mathrm{r}=0.524, \mathrm{p}=0.01)$ and Sperm DNAfragmentation index $(\mathrm{r}=0.482, \mathrm{p}<0.05)$ and an inverse relationship with total antioxidant capacity (TAC) $(\mathrm{r}=-0.542, \mathrm{p}<0.05)$. Antioxidant therapy significantly decreased glucose level, $18-40 \%(\mathrm{P}<0.05) ; \mathrm{HbA}_{1} \mathrm{C}$ 9-29\% $(\mathrm{P}<0.05)$; MDA level 33-41\%, $(\mathrm{P}<0.01)$; and Sperm DNA Fragmentation index, $23-33 \%,(\mathrm{p}<0.01)$ and increase in TAC, $27-36 \%$, $(\mathrm{p}<0.05)$.

\section{Discussion}

\section{Effect of insulin dependent diabetes on human spermatozoa}

The significant findings in the present study include the association between men with insulin dependent diabetes and impairment of quality of sperm such as asthenozoospermia and teratozoospermia that

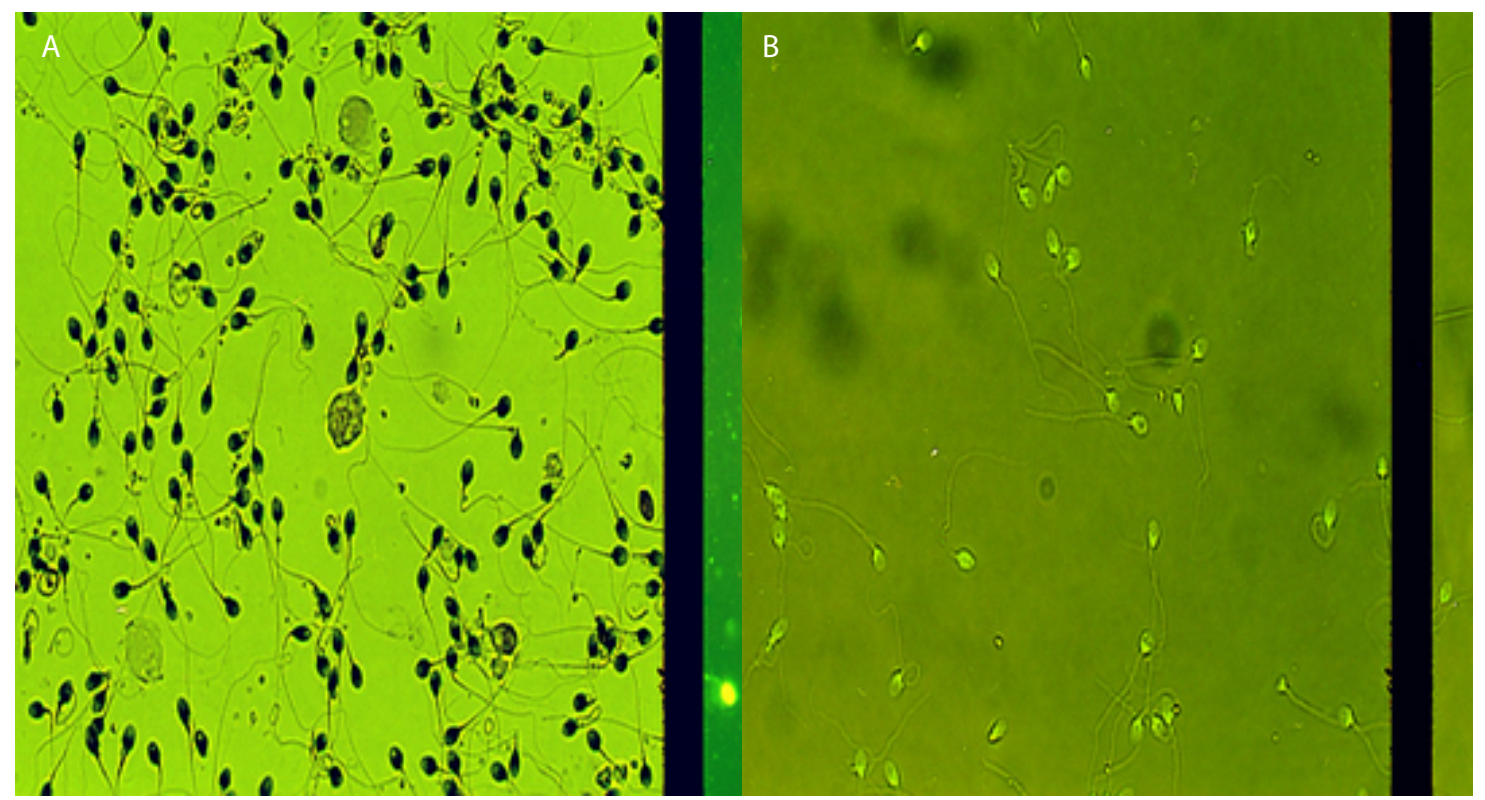

Figure 1:

a, b: $\times 100: \times 100$

a: Control Semen Specimen

b: Diabetic Semen specimen

Haematoxylin and Eosin stain of ejaculated human semen

a. Normal control showing normal sperm concentration and morphology.

b. Diabetic patient with sperm abnormalities such as double head (DH), and cytoplasmic mid-piece (cm) 
Citation: Omu AE, Al-Bader MD, Al-Jassar WF, Al-Azemi MK, Omu FE, et al. (2014) Antioxidants Attenuates the Effects of Insulin Dependent Diabetes Mellitus on Sperm Quality. Bioenergetics 3: 113. doi:10.4172/2167-7662.1000113

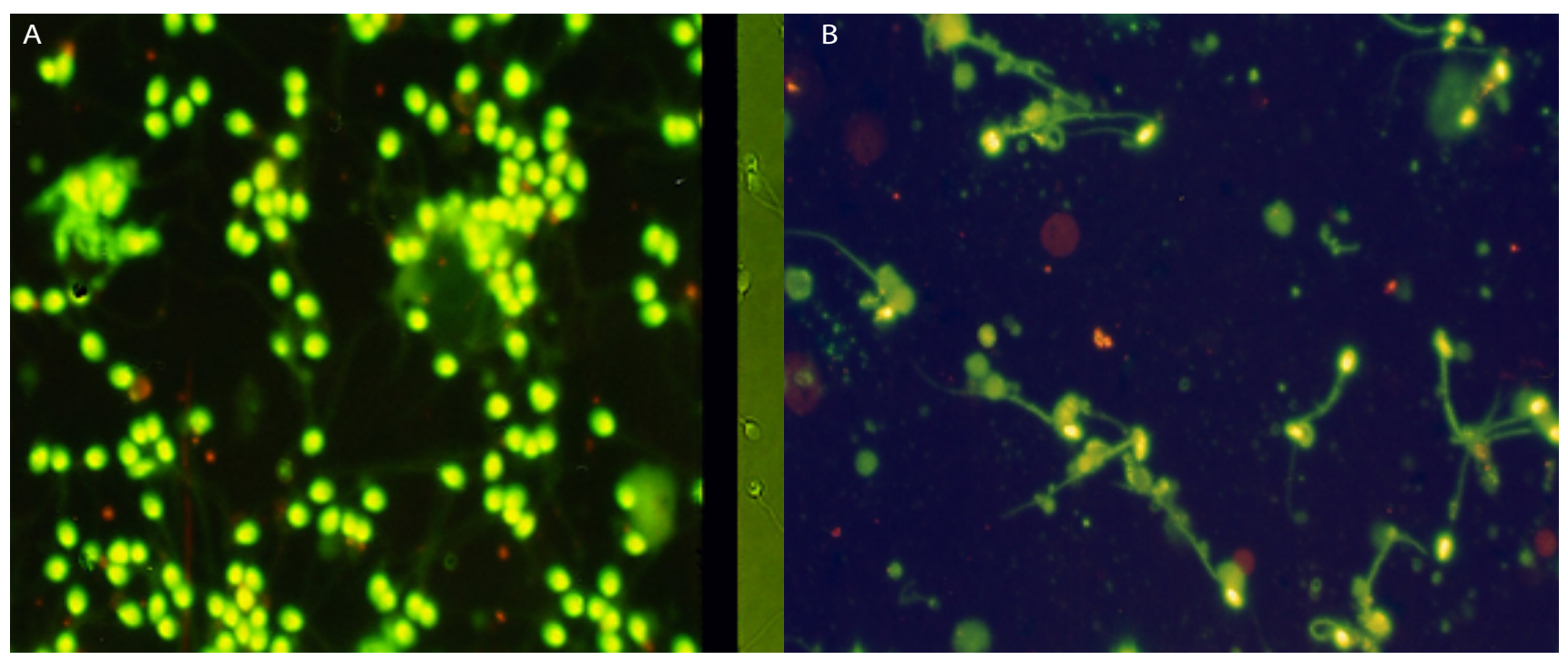

Figure 2a: Acridine Orange denaturation in Control Figure 2b: Acridine sperm denaturation in DM

Acridine denaturation of ejaculated human sperm. The range is from Green (normal sperm) (NS) as shown in

(a) Control group with mainly green stained sperm (b) A typical diabetic patient with denatured sperm stained red (RS) (Sperm DNA fragmentation) with yellowred, showing mild to moderate denaturation (Sperm DNA fragmentation in DM.

\begin{tabular}{|c|c|c|c|c|c|}
\hline Sperm Abnormalities & $\begin{array}{l}\text { All Diabetics } \\
\mathrm{N}=45\end{array}$ & $\begin{array}{l}\text { Diabetic A } \\
N=26\end{array}$ & $\begin{array}{l}\text { Diabetic B } \\
N=19\end{array}$ & $\begin{array}{l}\text { Controls } \\
\mathrm{N}=30\end{array}$ & $\begin{array}{l}\text { P Value } \\
\text { All diabetic vs Control }\end{array}$ \\
\hline Double head & $11(35.5)$ & $5(27.8)$ & $6(46.2)$ & $4(16)$ & 0.02 \\
\hline Large head & $9(29.0)$ & $4(22.2)$ & $5(38.5)$ & $5(20.0)$ & 0.05 \\
\hline Round spermatid & $8(25.8)$ & $4(22.2)$ & $4(30.8)$ & $2(8.0)$ & 0.01 \\
\hline Elongated spermatid & $6(19.4)$ & $3(16.7)$ & $3(23.0)$ & $1(4.0)$ & 0.04 \\
\hline Cytoplasmic mid piece & $8(25.8)$ & $3(16.7)$ & $5(38.8)$ & $1(4.0)$ & 0.01 \\
\hline Cytoplasmic tail & $4(12.9)$ & $2(11.1)$ & $2(15.4)$ & $1(4.0)$ & 0.05 \\
\hline Leukocytospermia & 10 (32.3) & $4(22.2)$ & $6(46.2)$ & $2(8)$ & 0.01 \\
\hline
\end{tabular}

Table 2: Comparison of sperm abnormalities in semen in diabetic men and non diabetic controls

Diabetic A- Men with insulin dependent diabetes mellitus with $\mathrm{HbA}_{1} \mathrm{c}<7 \%$ versus Diabetic $\mathrm{B}$ - Men with insulin dependent diabetes mellitus with $\mathrm{HbA}, \mathrm{c} \geq 7 \%$

Double head $\quad P<0.01$

Large head $\quad P<0.01$

Round spermatid $\quad P<0.05$

Cytoplasmic mid piece $\mathrm{P}<0.05$

Leukocytospermia $\quad \mathrm{P}<0.01$

All abnormalities are more common with diabetic men than control. Poor glycemic control was associated with more abnormalities than in diabetic with good glycemic control.

\begin{tabular}{|c|c|c|c|c|c|c|c|c|}
\hline & $\begin{array}{l}\text { All DM } \\
N=45\end{array}$ & $\begin{array}{l}\mathrm{A} 1 \\
\mathrm{~N}=26\end{array}$ & $\begin{array}{l}\mathrm{B} 1 \\
\mathrm{~N}=19\end{array}$ & $\begin{array}{l}\text { All } \\
\text { DM-2 N=41 }\end{array}$ & $\begin{array}{l}\mathrm{A} 2 \\
\mathrm{~N}=23\end{array}$ & $\begin{array}{l}B 2 \\
N=18\end{array}$ & A2-A1 (\%) & B2-B1 (\%) \\
\hline Semen volume (ml) & 3.6 & 3.6 & 3.6 & 3.7 & 3.8 & 3.6 & 2.8 & 5.6 \\
\hline Sperm count (million/ml) & 18.4 & 19.2 & 18.6 & 28.6 & 30.2 & 27.4 & 57.3 & 47.3 \\
\hline Progressive sperm motility (\%) & 25.6 & 26.2 & 24.6 & 34.6 & 36.2 & 33.1 & 38.2 & 34.6 \\
\hline Asthenozoospermia (\%) & 64.0 & 58 & 74 & 36 & 32.4 & 38.6 & 44.1 & 47.8 \\
\hline Normal morphology (\%) & 58.2 & 62.3 & 52.4 & 68.0 & 72.2 & 65.8 & 15.9 & 25.6 \\
\hline
\end{tabular}

Table 3: Effect of antioxidants on sperm parameters in men with insulin dependent diabetes

Four men did not complete the final phase of the study and they were therefore not included in the post therapy analysis. All DM1 - All diabetic men before antioxidant therapy and DM2- post therapy

$\mathrm{A} 1$ - Diabetic men with $\mathrm{HbA}, \mathrm{c}<7 \%$ and $\mathrm{B} 1-\mathrm{HbA}, \mathrm{c} \geq 7 \%$ before antioxidant therapy

A2 - Diabetic men with $\mathrm{HbA}_{1} \mathrm{c}<7 \%$ and $\mathrm{B} 2-\mathrm{HbA}_{1} \mathrm{c} \geq 7 \%$ after antioxidant therapy

Significant improvement in sperm parameters after antioxidant therapy

Sperm count -47 versus 57 percent $P<0.01$

Progressive motility 34 versus 38 percent $P<0.02$

Asthenozoospermia 44- versus 48 percent $\mathrm{P}<0.05$

Normal sperm morphology 16 versus $26 \mathrm{P}<0.01$ 
Citation: Omu AE, Al-Bader MD, Al-Jassar WF, Al-Azemi MK, Omu FE, et al. (2014) Antioxidants Attenuates the Effects of Insulin Dependent Diabetes Mellitus on Sperm Quality. Bioenergetics 3: 113. doi:10.4172/2167-7662.1000113

Page 6 of 9

\begin{tabular}{|c|c|c|c|c|c|c|c|}
\hline & Control $N=30$ & $\mathrm{~A}_{1}-\mathrm{HbA}_{1} \mathrm{c}<7 \%$ & $\mathrm{~B} 1-\mathrm{HbA}_{1} \mathrm{c} \geq 7 \%$ & $\mathrm{~A} 2-\mathrm{HbA}_{1} \mathrm{c}<7 \%$ & B2- $\mathrm{HbA}_{1} \mathrm{c} \geq 7 \%$ & $\mathrm{~A} 2-\mathrm{A}_{1}(\%)$ & B2-B1(\%) \\
\hline Glucose $(\mathrm{mmol} / \mathrm{L})$ & $4.8 \pm 1.8$ & $7.6 \pm 0.8$ & $11.4 \pm 2.3$ & $6.2 \pm 0.8$ & $6.8 \pm 1.2$ & 18.4 & 40.3 \\
\hline $\begin{array}{l}\text { TAC (mmol/L) } \\
\text { SOD (mmol/L) } \\
\text { GPX (mmol/L) }\end{array}$ & $\begin{array}{l}4.8 \pm 1.4 \\
2.8 \pm 1.2 \\
2.2 \pm 0.8\end{array}$ & $\begin{array}{l}3.3 \pm 1.2 \\
1.8 \pm 0.8 \\
2.0 \pm 1.2\end{array}$ & $\begin{array}{l}2.2 \pm 1.2 \\
1.4 \pm 0.8 \\
2.0 \pm 0.8\end{array}$ & $\begin{array}{l}4.2 \pm 1.4 \\
2.4 \pm 1.2 \\
2.2 \pm 1.2\end{array}$ & $\begin{array}{l}3.0 \pm 1.8 \\
1.9 \pm 1.2 \\
2.2 \pm 0.8\end{array}$ & $\begin{array}{l}27.3 \\
33.3 \\
10.0 \\
\end{array}$ & $\begin{array}{l}36.4 \\
35.7 \\
10.0\end{array}$ \\
\hline $\mathrm{HbA} 1 \mathrm{c} \%$ & $4.4 \pm 0.8$ & $6.4 \pm 2.1$ & $9.6 \pm 1.8$ & $5.8 \pm 1.4$ & $6.8 \pm 1.4$ & 9.4 & 29.2 \\
\hline MDA (mmol/L) & $1.4 \pm 0.4$ & $1.8 \pm 0.5$ & $2.4 \pm 0.8$ & $1.2 \pm 0.4$ & $1.4 \pm 0.6$ & 33.3 & 41.2 \\
\hline DFI \% & $8.0 \pm 2$ & $11.4 \pm 2.5$ & $14.2 \pm 3.4$ & $8.8 \pm 3.3$ & $10.4 \pm 3$ & 22.8 & 33.3 \\
\hline
\end{tabular}

Diabetic A- Men with insulin dependent diabetes mellitus with $\mathrm{HbA}_{1} \mathrm{c}<7 \%$ versus Diabetic $\mathrm{B}$ - Men with insulin dependent diabetes mellitus with $\mathrm{Hb} \mathrm{A}_{1} \mathrm{c} \geq 7 \%$

There are significant changes in the diabetic men except with glutathione peroxidase

Glucose $\quad P<0.01$

TAC $\quad P<0.01$

SOD $\quad \mathrm{P}<0.05$

GPX NS

MDA $\quad P<0.05$

DFI $\quad P<0.01$

There are more significant reduction in oxidant and increase in antioxidant status with initial poor glycaemic control ( $\mathrm{HbA}{ }_{1} \mathrm{c} \geq 7 \%$ ).

Table 4: Association between glucose level, $\mathrm{HbA}_{1} \mathrm{c}$ antioxidant status and sperm DNA fragmentation index

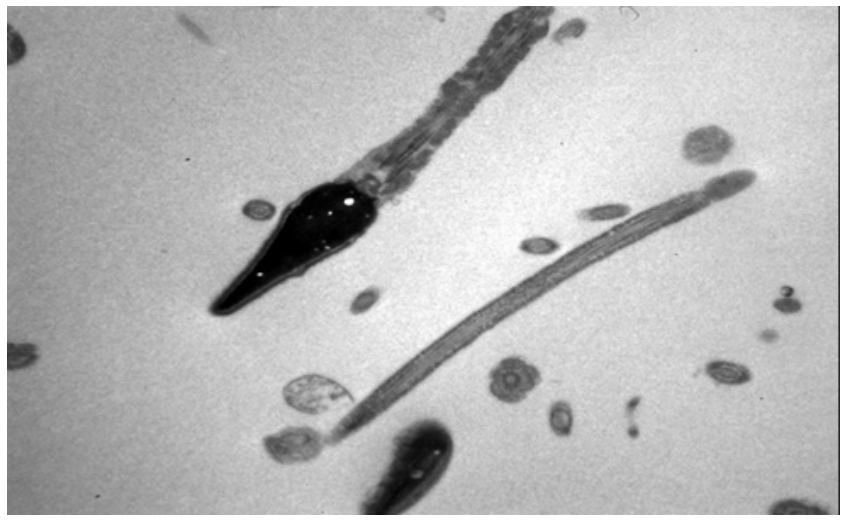

Figure 3a: x 400 Transmission Electron Microscopy of a non-diabetic patient (control) with normal sperm head $(\mathrm{NH})$ mid-piece with abundant mitochondria and normal tail (NT) and normal cross section with 9-2 n fibrils.

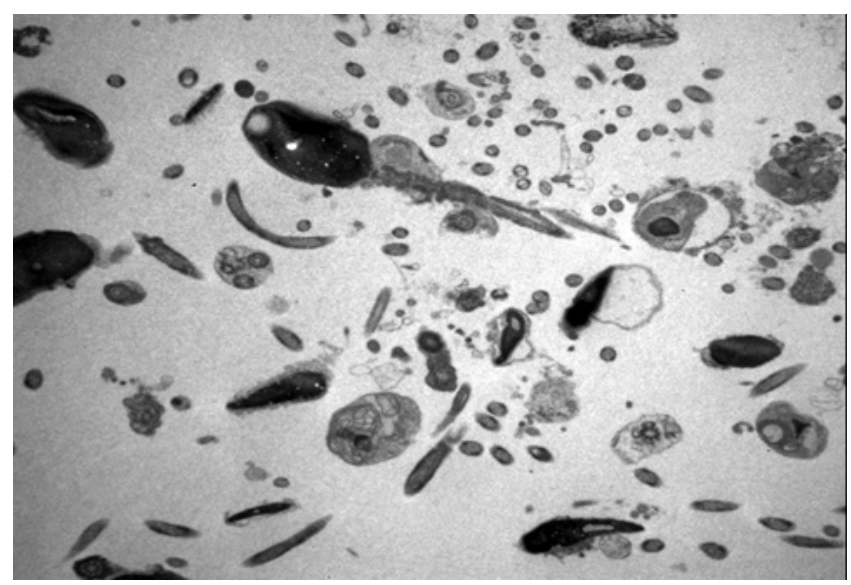

Figure 3b: Transmission Electron Microscopy of ejaculated semen of an insulin dependent diabetic man with infertility showing globular head $(\mathrm{GH})$, cytoplasmic mid-piece with scanty mitochondria, elongated (SSp) and round Spermatid (RSp), Secondary spermatocyte and apoptotic body (Ap).

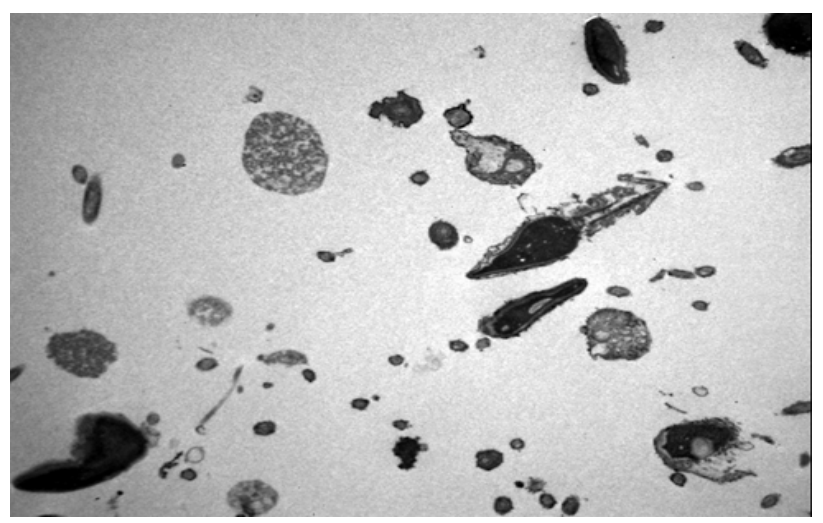

Figure 3c: Showing disruption of mitochondria and axonemal sheath and apoptotic bodies in a typical diabetic patient.
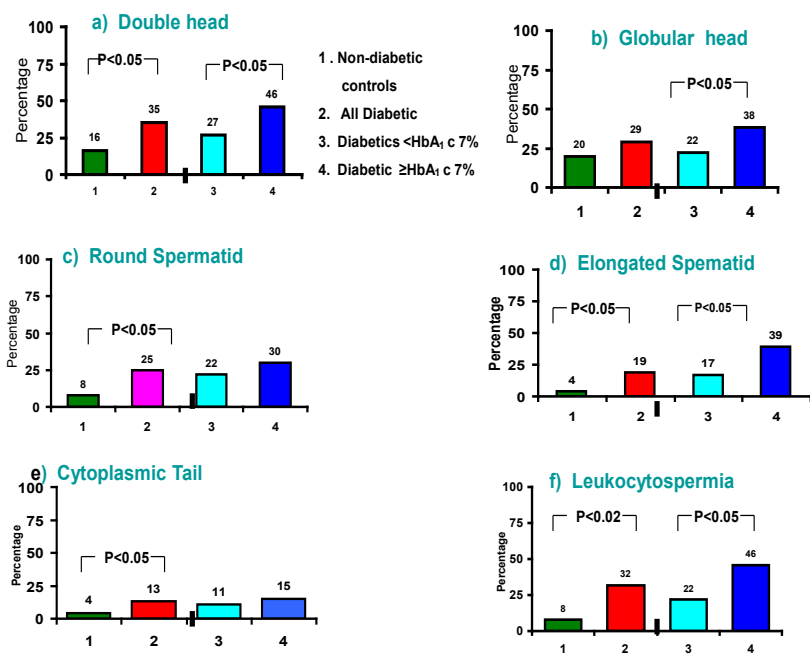

Figure 4: Sperm abnormalities. Sperm abnormalities in control non-diabetic compared with all diabetics, and poor glycaemic control. Double, round and globular sperm heads, elongated spermatid, cytoplasmic tail and leukocytospermia are more significantly common in the diabetic than control $(P<0.01)$ and more common with poor diabetic $\left(\mathrm{HbA}_{1} \mathrm{c} \geq 7 \%\right)$ than good control $\left(\mathrm{HbA}_{1} \mathrm{c}\right.$ $<7 \%)(\mathrm{P}<0.05)$ 


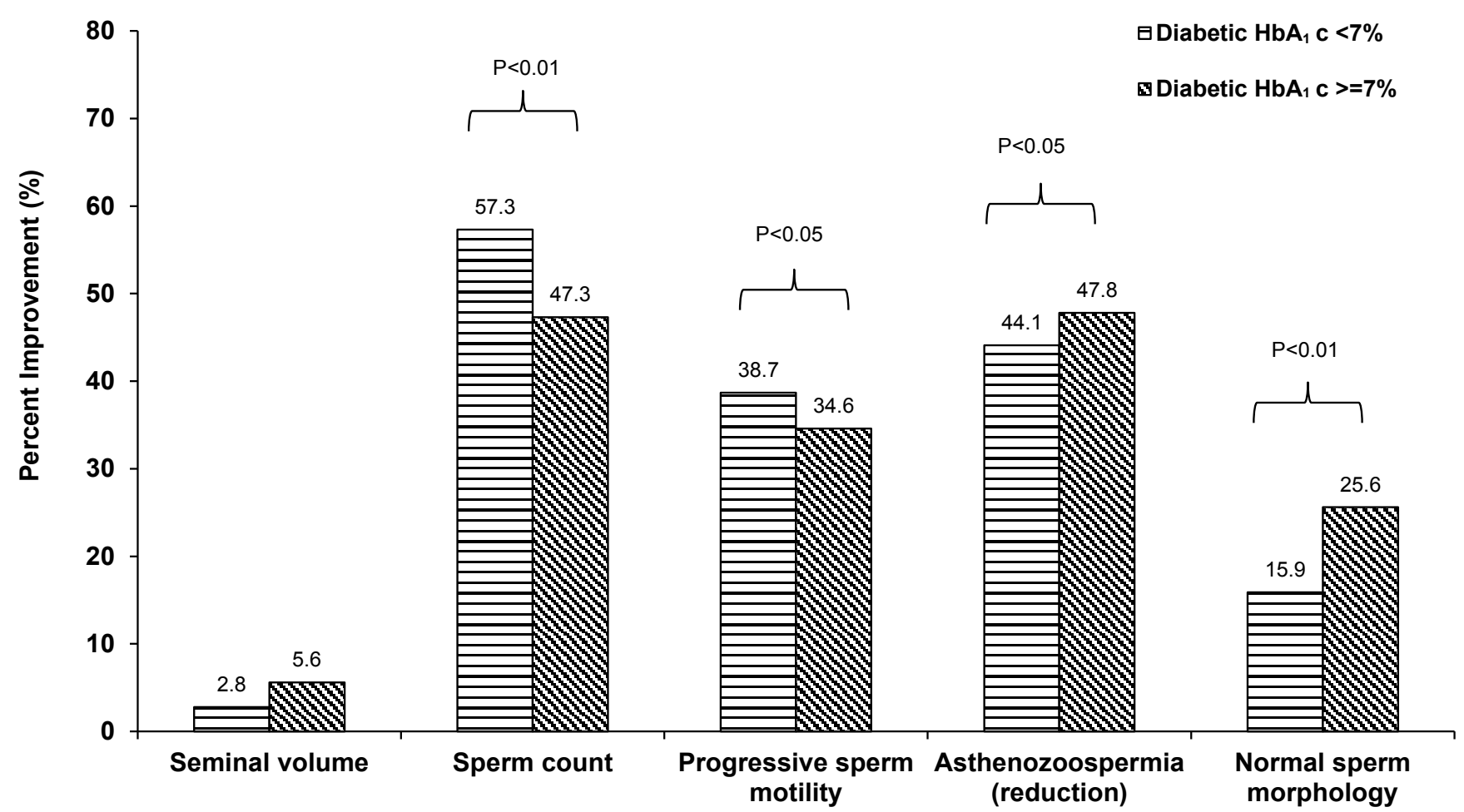

Figure 5: Effect of Antioxidant therapy on sperm parameters in men with insulin dependent diabetes mellitus.

Comparison of the outcome of antioxidant therapy between poor glycaemic control $\left(\mathrm{HbA}_{1} \mathrm{c} \geq 7 \%\right)$ and good glycemic control $(\mathrm{HbA},<7 \%)$. There is improvement all sperm parameters.

Initial good glycemic control is associated with more significant improvement with sperm count $(P<0.01)$ and progressive motility $(P<0.05)$.

Initial poor glycemic control shows more improvement with seminal volume $(P<0.05)$, reduction of asthenozoospermia and normal sperm morphology $(P<0.05)$.

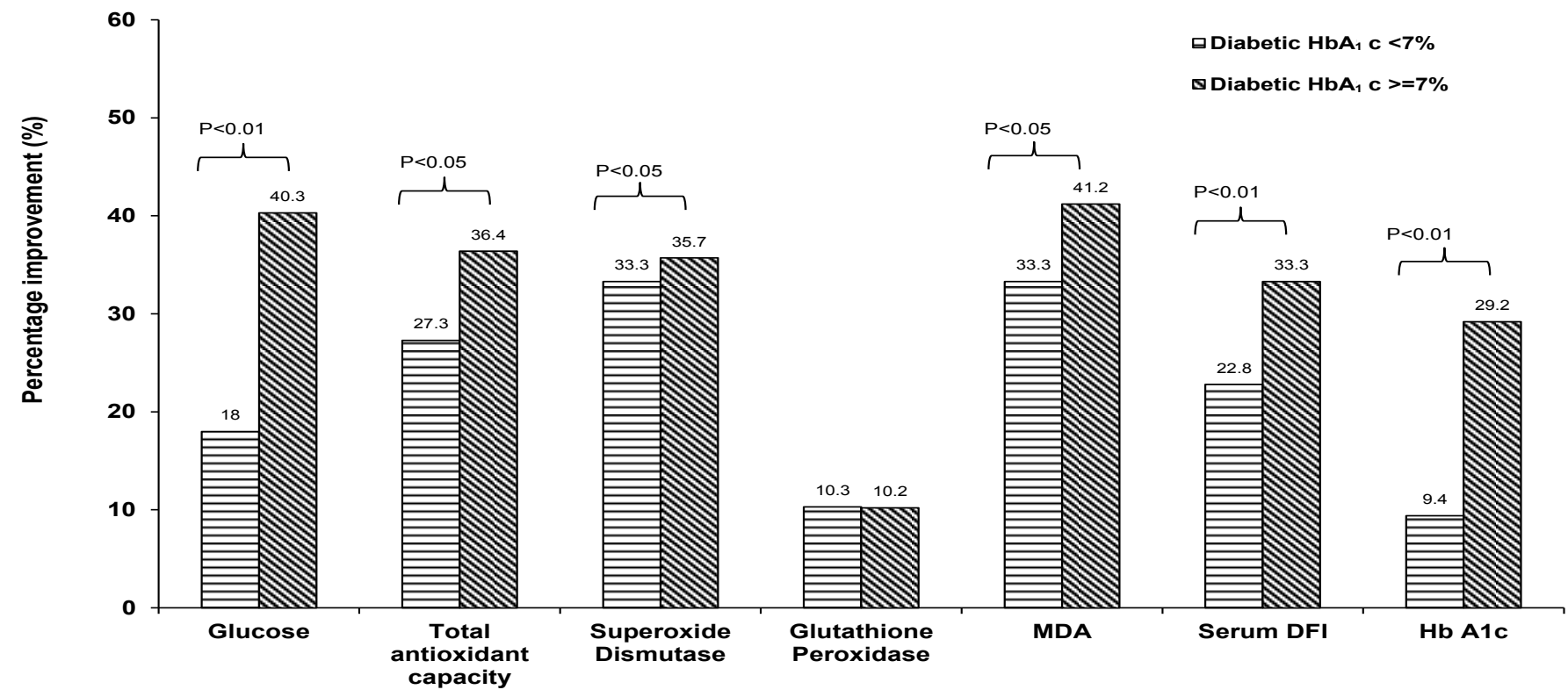

Figure 6: Effect of Antioxidant therapy on glucose levels, $\mathrm{HbA}_{1} \mathrm{C}$ antioxidant status and sperm DNA fragmentation index (DFI).

Evaluation of outcome of antioxidant therapy on glucose levels, $\mathrm{HbA}$, antioxidant status, and Sperm DNA fragmentation Index (DFI). There are significant improvements in serum glucose levels, MDA, $\mathrm{HbA}_{1} \mathrm{C}$ and $\mathrm{DFI}$ and TAC and SOD in all diabetic patients but more common in those with initial poor glycemic control $(\mathrm{P}<0.05$ to $\mathrm{P}<0.01$ ) than initial good glycemic control. Surprisingly, there was no difference with glutathione peroxidase. 
manifested as double heads, globuzoospermia and macrozoospermia and cytoplasmic mid and tail piece. This is in agreement with an earlier study in which diabetes mellitus of both type I and type II have adverse effects on male sexual and reproductive functions in adolescent boys and men in form of impairment of spermatogenesis, reduced sperm count, serum testosterone and seminal fluid volume, impotency, and loss of libido [24-26]. Diabetic men are certainly at a disadvantage in terms of sperm quality compared with healthy controls [12, 26-28].

The present study has revealed a number of possible factors to explain the phenomenon of how diabetes impacts sperm parameters. About 42.2 to $51.1 \%$ of patients in the present study had poor glycemic control. This could be as a result of non-compliance. An equally plausible factor may be insulin resistance which is tied up with low free testosterone [29], as shown in the present study in comparison with the control group. According to Ballester et al. [27] in insulindependent diabetes, Leydig cell function and testosterone production decrease because of the absence of the stimulatory effect of insulin on these cells and an insulin-dependent decrease in FSH and LH levels. The significant presence of round and elongated spermatid in semen of men with insulin dependent diabetes found in the present study may be a result of dysregulation of the process of spermiation in which mature spermatozoa are normally released into the adluminal compartment of the seminiferous tubule. The expression and secretion of insulin in human ejaculated spermatozoa has been demonstrated [30], thus providing an autocrine regulation of glucose metabolism according to their energetic needs independent of systemic insulin.

\section{Oxidative stress and poor glycaemic control: mechanism for sperm damage}

The present study showed a strong association between Diabetes and oxidative stress. The hallmark of poor glycemic control in diabetes mellitus is chronic hyperglycaemia, which is directly associated with production and release of free radicals and oxidative stress $[31,32]$ with higher levels of malonedialdehyde and reduced antioxidant activity. Glycemic control seems to be a significant factor in the aetiology of abnormality of human sperm (teratozoospermia) and sperm DNA fragmentation. Leukocytospermia and immature spermatozoa with cytoplasmic mid and tail piece were common findings among diabetic men in the present study. Both enhance Oxidative stress and result in male infertility and developmental abnormalities [25].

\section{Role for antioxidants}

A significant finding of present study is the improvement of sperm parameters associated with antioxidant therapy; for sperm concentration 47 to $57 \%$, progressive motility 34 to $38 \%$, asthenozoospermia 44 to $48 \%$ and normal sperm morphology 16 to $26 \%$. This shows that antioxidants therapy may improve spermatogenesis including spermiation, intercept and prevent the onslaught of oxidative stress on human spermatozoa, thus prevent impairment of sperm motility, especially in the genital tract.By scavenging of free radical to prevent oxidative stress, antioxidant also prevents sperm DNA damage, as demonstrated in the present study and others $[24,33]$. It is of clinical interest that combined antioxidant therapy was associated with reduction of blood glucose in poor and good glycemic control, in the present study. This is consistent with studies in which Zinc supplementation in diabetes has been associated with reduction of blood glucose and dyslipidemia [34,35] and antioxidants improved insulin sensitivity, by reducing oxidative stress and insulin resistance [36]. Zinc improves sperm quality on its own as a membrane stabilizer, and as a component of superoxide dismutase prevents sperm apoptosis and sperm DNA fragmentation.
The men with insulin dependent diabetes certainly need tight glycaemic control with insulin. In addition, lifestyle changes in diet rich in natural antioxidants such as vitamins $\mathrm{C}$ and $\mathrm{E}$ or/and daily supplementation are advocated. Combining the antioxidants has been advocated because of their different effects on parameters of insulin sensitivity and lipid metabolism [36].

\section{Conclusion}

Diabetes mellitus has a significant impact on the fertility through impaired sperm quality through oxidative stress. Antioxidant therapy has been shown to significantly improve the sperm quality in men with insulin-dependent diabetes mellitus through reduction of oxidative stress and improvement of the antioxidant status.

\section{Acknowledgement}

The study was supported by research facilities by different projects by the principal investigator in MLO 0431, MO 031 and MO 033 funded by Research Administration, Kuwait University.

\section{References}

1. Wild S, Roglic G, Green A, Sicree R, King H (2004) Global prevalence of diabetes: estimates for the year 2000 and projection for 2030. Diabetes Care 27: 1047-1053

2. Shaw JE, Sicree RA, Zimmet PZ (2010) Global estimates of the Prevalence of diabetes for 2010 and 2030. Diabetes Res Clin Pract 87: 4-14.

3. Ahmed F, Waslien C, Al-Sumaie M, Prakash P, Allafi A (2013) Trends and risk factors of hyperglycemia and diabetes among Kuwaiti adults: National Nutrition Surveillance Data from 2002 to 2009. BMC Public Health 13: 103.

4. Alqurashi KA, Aljabri KS, Bokhari SA (2011) Prevalence of diabetes mellitus in Saudi Community. Ann Saudi Med 31: 19-23.

5. Moussa MA, Alsaeid M, Abdella N, Refai TM, Al-Sheikh N, et al. (2008) Prevalence of type 2 diabetes mellitus among Kuwaiti children and adolescents. Med Princ Pract 17: 270-275

6. Amaral S, Oliveira PJ, Ramalho-Santos J (2008) Diabetes and the impairment of reproductive function: possible role of mitochondria and reactive oxygen species. Curr Diabetes Rev 4: 46-54.

7. Standard of Medicare in Diabetes-2010 (2010) American Diabetes Association Diabetes Care 33: 4-5.

8. Brownlee M (2001) The Pathobiology of Diabetic Complications: a unifying mechanism. Diabetes 54: 1615-1625.

9. Agbaje LM, Rogers DA, McVicar CM, McClure N, Atkinson AB, et al. (2007) Insulin dependent diabetes mellitus: implications for male reproductive function. Hum Reprod 22: 1871-1877.

10. Forbes JM, Coughlan MT, Cooper ME (2008) Oxidative stress as a majo culprit in kidney disease. Diabetes 57: 1446-1454.

11. Akondi RB, Kumar P, Annapurna A, and Pujari M (2011) Protective Effect of Rutin and Naringin on Sperm Quality in Streptozotocin (STZ) Induced Type 1 Diabetic Rats. Iran J Pharm Res 10: 585-596.

12. La Vignera S, Condorelli R, Vicari E, D'Agata R, Calogero AE (2012) Diabetes mellitus and sperm parameters. J Androl 33: 145-153.

13. Mallidis C, Agbaje I, McClure N, Kliesch S (2011) The influence of diabetes mellitus on male reproductive function: a poorly investigated aspect of male infertility. Urologe A 50: 33-37.

14. Bal R, Türk G, Tuzcu M, Yilmaz O, Ozercan I, et al. (2011) Protective effects of nanostructures of hydrated $\mathrm{C} 60$ fullerene on reproductive function in streptozotocin-diabetic male rats. Toxicology 282: 69-81.

15. Ateşşahin A, Türk G, Yilmaz S, Sönmez M, Sakin F, et al. (2010) Modulatory effects of lycopene and ellagic acid on reproductive dysfunction induced by polychlorinated biphenyl (Aroclor 1254) in male rats. Basic Clin Pharmacol Toxicol 106: 479-489.

16. Çeribaşı AO, Sakin F, Türk G, Sönmez M, Ateşşahin A (2012) Impact of ellagic acid on adriamycin-induced testicular histopathological lesions, apoptosis, lipid peroxidation and sperm damages. Exp Toxicol Pathol 64: 717-724. 
Citation: Omu AE, Al-Bader MD, Al-Jassar WF, Al-Azemi MK, Omu FE, et al. (2014) Antioxidants Attenuates the Effects of Insulin Dependent Diabetes Mellitus on Sperm Quality. Bioenergetics 3: 113. doi:10.4172/2167-7662.1000113

Page 9 of 9

17. Rolf C Cooper TG, Yeung CH, Nieschlag E (1999) Antioxidant treatment of patients with asthenozoospermia or moderate oligoasthenozoospermia with high-dose vitamin $\mathrm{C}$ and vitamin E: a randomized, placebo-controlled, doubleblind study. Hum Reprod 14: 1028-1033.

18. Scott R, MacPherson A, Yates RW (1998) The effect of oral selenium supplementation on human sperm motility. Br J Urol 82: 76-80.

19. Omu AE, Al-Qattan F, Abdulhadi F, Fernandes S (1999) Seminal immune response in infertile men with leukocytospermia: effect on antioxidant activity. Eur J Obstet Gynecol Reprod Biol 86: 195-202.

20. Alves MG, Martins AD, Rato L, Moreira PI, Socorro S, et al. (2013) Molecular mechanisms beyond glucose transport in diabetes-related male infertility. Biochim Biophys Acta 1832: 626-635.

21. Rato L, Alves MG, Dias TR, Lopes G, Cavaco JE, et al. (2013) High-energy diets may induce a pre-diabetic state altering testicular glycolytic metabolic profile and male reproductive parameters. Andrology 1: 495-504.

22. World Health Organization (1999) WHO Laboratory Manual for the Examination of Human Semen and Sperm-Cervical Mucus Interaction. (4thedn), Cambridge University Press, Cambridge, UK.

23. Evenson D, Jost $L$ (2000) Sperm chromatin structure assay is useful for fertility assessment. Methods Cell Sci 22: 169-189.

24. Agarwal A, Said TM (2005) Oxidative stress, DNA damage and apoptosis in male infertility: a clinical approach. BIU Int 95: 503-507.

25. Gil-Guzman E, Ollero M, Lopez MC, Sharma RK, Alvarez JG, et al. (2001) Differential production of reactive oxygen species by subsets of human spermatozoa at different stages of maturation. Hum Reprod 16: 1922-1930.

26. Glenn DR, McClure N, Lewis SE (2003) The hidden impact of diabetes on male sexual dysfunction and fertility. Hum Fertil (camb) 6: 174-179.
27. Ballester J, Muñoz MC, Dominguez J, Rigau T, Guinovart JJ, et al. (2004) Insulin-Dependent Diabetes Affects Testicular Function by FSH- and LHLinked Mechanisms. J Androl 25: 706-719.

28. Baccetti B, La Marca A, Piomboni P, Capitani S, Bruni E, et al. (2002) Insulin-dependent diabetes in men is associated with hypothalamo-pituitary derangement and with impairment in semen quality. Hum Reprod 17: 26732677.

29. Omu AE (2013) Sperm Parameters: paradigmatic index of good health and longevity. Med Princ Pract 22: 30-42.

30. Aquila S, Gentile M, Middea E, Catalano S, Ando S (2005) Autocrine regulation of insulin secretion in human ejaculated spermatozoa. Endocrinology 146: 552 557.

31. Marfella R, Quagliaro L, Nappo F, Ceriello A, Giugliano D (2001) Acute hyperglycemia induces an oxidative stress in healthy subjects. J Clin Invest 108: 635- 636

32. Kodoma H, Yamaguchi R, Fukuda J, Kasai H, Tanaka T (1997) Increased oxidative deoxyribonucleic acid damage in the spermatozoa of infertile male patients. Fertil Steril 68: 519-524.

33. Zeisel SH (2004) Antioxidant Suppress Apoptosis. J Nutr 134: 3179-3180.

34. El-Ashmony SMA, Morsi HK, Abdelhafez AM (2012) Effect of Zinc supplementation on glycemic control, lipid profile, and renal function in patients with type 2 diabetes: a single blinded, randomized, placebo-controlled trial. J Biol Agric and Healthcare 2: 33-41.

35. Omu AE, Al-Azemi MK, Kehinde EO, Anim JT, Oriowo MA, et al. (2008) Indications of the mechanisms involved in the improved Sperm parameters by zinc therapy. Med Princ and Pract 17: 108-116.

36. Udupa AS, Nahar PS, Shah SH, Kshirsagar MJ, Ghongane BB (2012) Study of comparative effects of antioxidants on insulin sensitivity in type 2 diabetes mellitus. J Clin Diagn Res 6: 1469-1473. 